Gene expression pattern

\title{
CMIX, a paired-type homeobox gene expressed before and during formation of the avian primitive streak
}

\author{
Stefan Stein ${ }^{1}$, Tobias Roeser ${ }^{2}$, Michael Kessel* \\ Max-Planck-Institut für biophysikalische Chemie, Abteilung Molekulare Zellbiologie, Am Fassberg, D-37077 Göttingen, Germany
}

Received 1 April 1998; revised version received 15 May 1998; accepted 26 May 1998

\begin{abstract}
We cloned a chicken homeobox gene closely related to the Xenopus Mix.1 gene. CMIX is expressed early in embryogenesis in a sickleshaped area in the posterior zone of the blastoderm. With the beginning of gastrulation, $C M I X$ transcripts are found in the primitive streak primordium, then in the young and medium-sized streak, however not in the mesoderm after its emergence. In the fully-extended streak, CMIX is restricted to its middle, i.e. the prospective ventral mesoderm. CMIX RNA is undetectable by whole-mount in-situ analysis in later stages. We compare CMIX expression to the early pattern of the brachyury gene. (C) 1998 Elsevier Science Ireland Ltd. All rights reserved
\end{abstract}

Keywords: CMIX; Homeobox; Chick; Mesoderm; Primitive streak; Gastrulation

In Xenopus the two closely-related genes Mix.1 (Rosa, 1989) and Mix.2 (Vize, 1996) together with the recently described Milk gene (V. Ecochard et al., unpublished data, but see GenBank accession number: AF005999) define a distinct subtype of the paired class homeobox genes. The two, possibly pseudo-allelic Mix genes are expressed in indistinguishable patterns, beginning immediately after the midblastula transition in the vegetal half of the embryo, mainly in the presumptive endoderm. Later the expression domain includes part of the prospective mesoderm in the marginal zone and with onset of gastrulation expression is restricted to the ventral mesoderm (see also http://vize222.zo.utexas.edu). The Mix genes respond by immediate early transcriptional activation to signals of TGF- $\beta$ family members like activin, Vg-1, TGF- $\beta$, and BMP4 (Rosa, 1989; Huang et al., 1995; Chen et al., 1996; Vize, 1996). Dorsal mesoderm is re-specified to a ventral fate by the ectopic

\footnotetext{
* Corresponding author. Tel.: +49 551 2011560; fax: +49 551 2011504; e-mail: mkessell@.gwdg.de

${ }^{1}$ Present address: Max-Planck-Institut für biophysikalische Chemie, Abteilung Molekulare Entwicklungsbiologie, Am Fassberg 11, D-37077 Göttingen, Germany.

${ }^{2}$ Present address: Max-Planck-Institut für Entwicklungsbiologie, Abteilung Genetik, Spemannstr. 35, D-72076 Tübingen, Germany.
}

action of Mix.1 homodimers, but Mix.1 misexpression cannot induce secondary axes or mesoderm per se. Thus the Mix homeodomain factors seem to be important determinants necessary for the establishment of ventral mesoderm identity. Despite considerable efforts (e.g. Hermesz et al., 1996) no Mix type homeobox gene has been identified from non-amphibian sources so far. Here we report the isolation of cDNAs from early chick embryos, which clearly belong to the Mix typus based on sequence and expression analysis.

Mix-related DNA fragments could be amplified with degenerated primers designed to fit the $5^{\prime}$ and $3^{\prime}$ ends of the Xenopus Mix. 1 homeobox from Xenopus, but not from chicken embryonic RNA. Therefore, a cDNA library prepared from chicken $\mathrm{HH}^{+} / 4$ nodes was screened under low stringency conditions applying the Xenopus PCR fragments as probes. Two overlapping cDNA clones were obtained and sequenced (Accession number: AJ004903; EMBL Nucleotide Sequence Database). The encoded ' $C M I X$ ' homeodomain is $69 \%$ identical to Mix.1/Mix.2, and $57 \%$ identical to the Milk homeo domain (Fig. 1). Although the name assigned to this gene acknowledges its close relationship to the Xenopus Mix. 1 and Mix. 2 genes, a clear understanding of the degree of functional homology requires further study. The next-closest relatives are the $0 t x 2$ and 


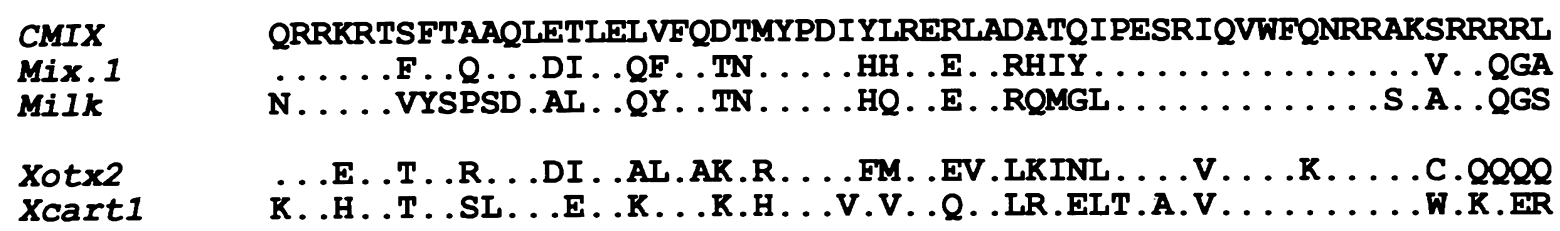

Fig. 1. Alignment of Mix homeodomains and their closest relatives. Dots represent residues identical to the $C M I X$ sequence. Note the methionine at position 24 of the Mix homeodomains, which can not be found in any other of the paired class homeodomain proteins at this position. All sequences except $C M I X$ are from Xenopus. The homeodomain of Mix.2 is identical to Mix.1. Xcart1 is from GenBank accession number U15276; for further references see text.

the Cart1 genes (Fig. 1). There is little sequence-similarity of $C M I X$ to the other proteins outside the homeodomain. The $C M I X$ gene we report is also described in a parallel work (Peale et al., 1998). This cDNA is distinguished by a 221-bp insertion in the coding region, resulting in alternative reading frames in the $3^{\prime}$ end of the gene, involving a replacement of RRL (Fig. 1) at the end of the homeodomain by QRG.

In situ hybridizations were performed to trace the expression of the CMIX gene in chick embryogenesis (Fig. 2). Embryos were staged according to Eyal-Giladi and Kochav (1976) and Hamburger and Hamilton (1951). The first transcripts are detectable before formation of the primitive streak in the posterior marginal zone in a crescent-shaped domain (Fig. 2A). CMIX-expressing cells reside not only in the epiblast but also in deeper layers (Fig. 2I,J). During the following stages the laterally-extending expression domain narrows to the embryonic midline and the primitive streak primordium. Concomitantly the population of CMIXexpressing cells becomes more densely packed than during the earlier stages (Fig. 2B,C). In stage $\mathrm{HH} 3$ to $\mathrm{HH}^{+}$the entire primitive streak except for its very posterior part is strongly positive for $C M I X$ (Fig. 2D,E). Transverse sections show that it marks the epiblast as well as the streak mesoderm, while most of the mesoderm that already emerged from the streak, and the endoderm does not express (Fig. $2 \mathrm{~K}-\mathrm{M})$. Shortly before the primitive streak reaches its full extension, CMIX RNA becomes restricted to prospective ventral mesoderm in middle-to-posterior portions of the streak, leaving out the anterior part including Hensen's node (Fig. 2G). During further development CMIX transcription is rapidly downregulated also in the middle of the streak and after completion of head-process formation (HH6) CMIX expression is no longer detectable (Fig. 2H; examined up to the 22-somite stage, not shown).

The principal similarities between MIX gene expression in chicken and Xenopus become obvious especially in comparison to other genetic markers. In early Xenopus embryos, Mix characterizes the late, i.e. post-MBT vegetal cells, and brachyury becomes induced at the interphase to the Xotx2
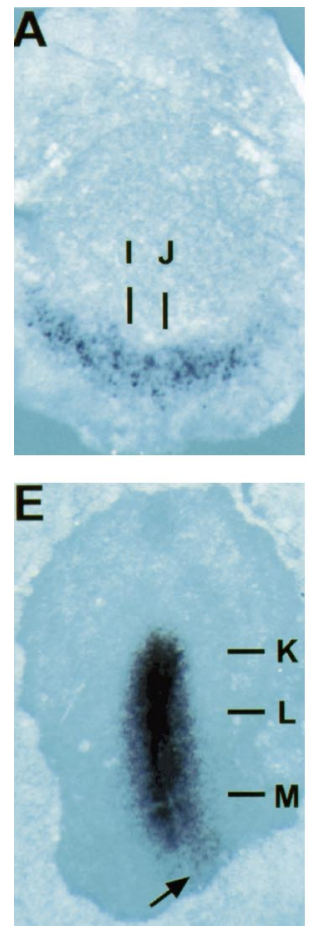
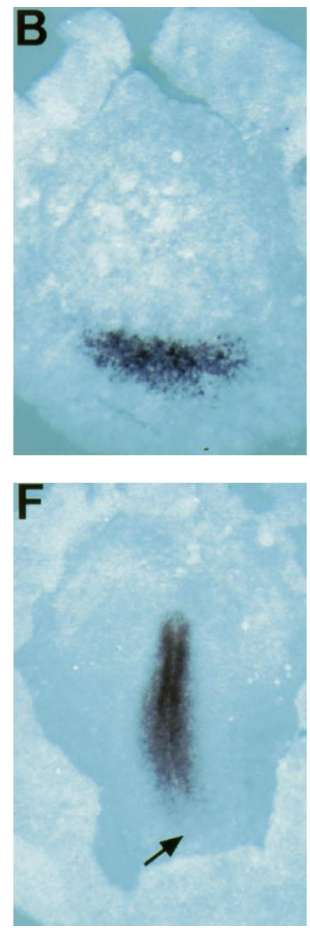
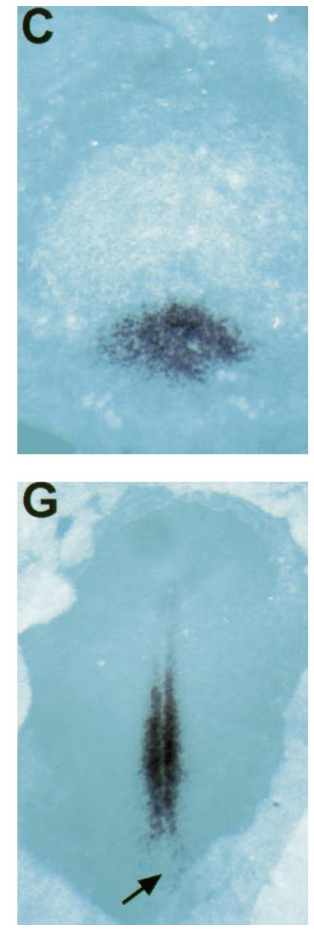
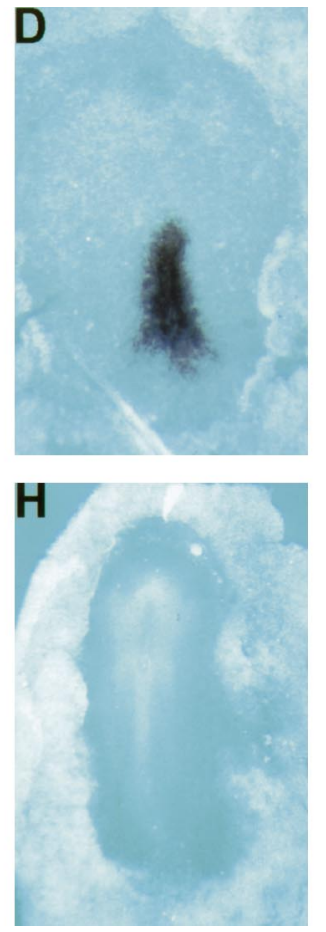
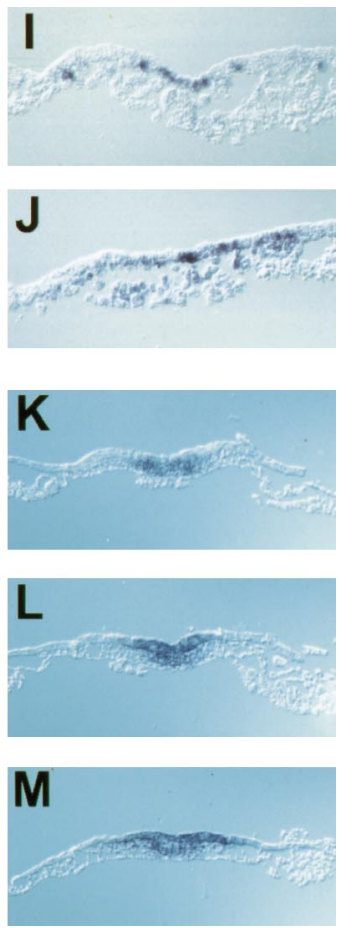

Fig. 2. Distribution of $C M I X$ transcripts during chick embryogenesis. For description and discussion see text. (A) EK stage XII. (B) stage HH1. (C) HH2 ${ }^{-}$. (D) HH3. (E) $\mathrm{HH}^{+}$. (F) $\mathrm{HH}^{-}$. (G) HH4. (H) HH6. Arrows indicate lack of expression in the posterior streak, lines indicate direction and levels of sections shown in $\mathrm{I}-\mathrm{M}$. 

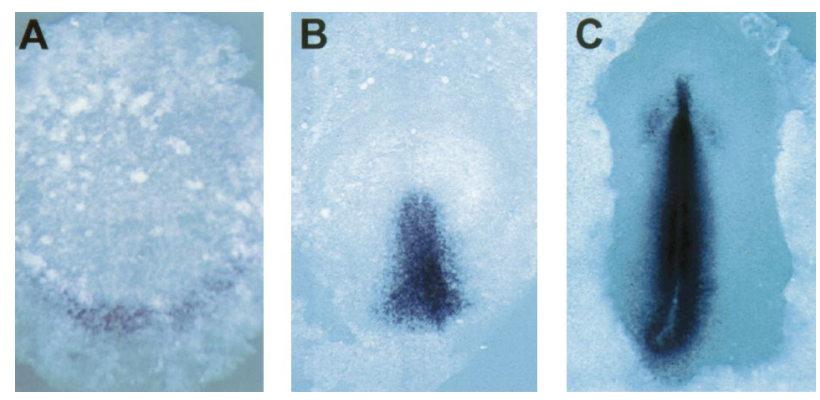

Fig. 3. Early pattern of the chicken brachyury gene. Brachyury expression (Kispert et al., 1995; Knezevic et al., 1997). (A) EK stage XII. (B) HH3. (C) HH5.

expressing animal half (Smith et al., 1991; Pannese et al., 1995). A comparison of the homologs of the same three genes in chick embryos reveals a quite similar situation. $C$-otx 2 characterizes the majority of the epi- and hypoblast (Bally-Cuif et al., 1995), CMIX lies at the opposing posterior marginal zone (Fig. 2A) and brachyury at the interphase or the overlap (Fig. 3A). During primitive streak formation, brachyury appears first as a panmesodermal marker similar to CMIX (Fig. 3B), but then is maintained in the streak and in the late dorsal mesoderm, the notochord, after ingression (Fig. 3C). C-otx2 becomes restricted to dorsal/anterior structures, the node and the prospective fore- and midbrain (Bally-Cuif et al., 1995). The earliest brachyury domain detected in chick embryos (Knezevic et al. (1997) Fig. 3A) confirms the recent finding of brachyury expression between the extraembryonic and embryonic part of the mouse egg cylinder (Thomas and Beddington, 1996), and may identify the earliest site of mesoderm induction in these two amniota. An intriguing similarity exists between the early expression patterns of $C M I X$ and the chicken $\mathrm{cVg} I$ gene (Seleiro et al., 1996; Shah et al., 1997), a homolog of the vegetally expressed frog factor $V g l$ (Huang et al., 1995). Processed Vg1 is sufficient for ectopic induction of Mix-genes in Xenopus animal cap explants, and ectopic $\mathrm{cVg} 1$ induces primitive streak formation (Huang et al., 1995; Shah et al., 1997). In conclusion, based on sequence and expression, we have isolated the first non-amphibian Mix-type homeobox gene.

\section{Acknowledgements}

We thank B. Herrmann for the chicken brachyury probe, and E. Bellefroid for a gift of Xenopus RNA. The technical assistance of W. Behrens is gratefully acknowledged. This work was supported by the Max-Planck-Society and DFG grant SFB271/A3.

\section{References}

Bally-Cuif, L., Gulisano, M., Broccoli, V., Boncinelli, E., 1995. c-otx2 is expressed in two different phases of gastrulation and is sensitive to retinoic acid treatment in chick embryo. Mech. Dev. 49, 49-63.

Chen, X., Rubock, M.J., Whitman, M., 1996. A transcriptional partner for MAD proteins in TGF-b signalling. Nature 383, 691-696.

Eyal-Giladi, H., Kochav, S., 1976. From cleavage to primitive streak formation: a complementary normal table and a new look at the first stages of the development of the chick. I. General morphology. Dev. Biol. 49, 321-337.

Hamburger, V., Hamilton, H.L., 1951. A series of normal stages in the development of the chick embryo. J. Morphol. 88, 49-92.

Hermesz, E., Mackem, S., Mahon, K.A., 1996. Rpx - a novel anteriorrestricted homeobox gene progressively activated in the prechordal plate, anterior neural plate and Rathke's pouch of the mouse embryo. Development 122, 41-52.

Huang, H.-C., Murtaugh, L.C., Vize, P.D., Whitman, M., 1995. Identification of a potential regulator of early transcriptional responses to mesoderm inducers in the frog embryo. EMBO J. 14, 5965-5973.

Knezevic, V., De Santo, R., Mackem, S., 1997. Two novel chick T-box genes related to mouse brachyury are expressed in different, non-overlapping mesodermal domains during gastrulation. Development 124, 411-419.

Kispert, A., Ortner, H., Cooke, J., Herrmann, B.G., 1995. The chick Brachyury gene: developmental expression pattern and response to axial induction by localized activin. Dev. Biol. 168, 406-415.

Pannese, M., Polo, C., Andreazzoli, M., Vignali, R., Kablar, B., Barsacchi, G., Boncinelli, E., 1995. The Xenopus homologue of Otx2 is a maternal homeobox gene that demarcates and specifies anterior body regions. Development 121, 707-720.

Peale, F.P., Sugden, L. and Bothwell, M., 1998. Characterization of CMIX, a chicken homeobox gene related to the Xenopus gene Mix.1. Mech. Dev. 75, 167-170.

Rosa, F.M., 1989. Mix.1, a homeobox mRNA inducible by mesoderm inducers, is expressed mostly in the presumptive endodermal cells of Xenopus embryos. Cell 57, 965-974.

Seleiro, E.A.P., Connolly, D.J., Cooke, J., 1996. Early developmental expression and experimental axis determination by chicken $V g 1$ gene. Curr. Biol. 6, 1476-1486.

Shah, S.B., Skromne, I., Hume, C.R., Kessler, D.S., Lee, K.J., Stern, C.D., Dodd, J., 1997. Misexpression of chick $V g l$ in the marginal zone induces primitive streak formation. Development 124, 5127-5138.

Smith, J.C., Price, B.M., Green, J.B., Weigel, D., Herrmann, B.G., 1991. Expression of a Xenopus homolog of Brachyury (T) is an immediateearly response to mesoderm induction. Cell 67, 79-87.

Thomas, P., Beddington, R., 1996. Anterior primitive endoderm may be responsible for patterning the anterior neural plate in the mouse embryo. Curr. Biol. 6, 1487-1496.

Vize, P.D., 1996. DNA sequences mediating the transcriptional response of the Mix.2 homeobox gene to mesoderm induction. Dev. Biol. 177, 226-231 